\title{
A systematic review of the keystone design perforator island flap in the reconstruction of trunk defects
}

\author{
Irena Sakura Rini ${ }^{1}$, Alberta Jesslyn Gunardi ${ }^{1}$, Renate Parlene Marsaulina ${ }^{1}$, Teguh Aryandono ${ }^{2}$, \\ Ishandono Dachlan ${ }^{3}$, Iwan Dwiprahasto ${ }^{4}$ \\ ${ }^{1}$ Department of Plastic Surgery, Dharmais Cancer Hospital, West Jakarta; Divisions of ${ }^{2}$ Oncology Surgery and ${ }^{3}$ Plastic and Reconstructive \\ Surgery, Department of Surgery, Dr. Sardjito Hospital, Faculty of Medicine, Public Health and Nursing, Universitas Gadjah Mada, \\ Yogyakarta; ${ }^{4}$ Department of Pharmacology and Therapy, Faculty of Medicine, Public Health and Nursing, Universitas Gadjah Mada, \\ Yogyakarta, Indonesia
}

The keystone design perforator island flap can be utilized in the repair of trunk defects. A systematic review was carried out to identify the complication rates of the use of this flap to treat such defects. The MEDLINE, Embase, Cochrane Library, and PubMed Central databases were searched for articles published between January 2003 and December 2018 that reported the use of keystone design perforator island flaps in the repair of trunk defects. Study selection was conducted in alignment with the Preferred Reporting Items for Systematic Reviews and Meta-Analyses statement. Eight articles involving a total of 54 flaps satisfied the inclusion criteria. The most frequently reported cause of trunk defects was oncologic resection (64.4\%). The overall complication rate was 35.2\%, and complications included infection $(11.1 \%)$, wound dehiscence $(7.4 \%)$, delayed healing $(7.4 \%)$, and partial flap loss $(1.9 \%)$. The keystone design perforator island flap is associated with a high success rate and low technical complexity. Despite minor complications, keystone design flaps could be a preferred choice for trunk reconstruction.

Keywords Perforator flap / Reconstructive surgical procedures / Torso / Systematic review
Correspondence: Irena Sakura Rini Department of Plastic Surgery, Dharmais Cancer Hospital, Bagian Bidang Medik It.6 Gedung Direksi, RS Kanker Dharmais, Jl. Let. Jendral S Parman Kav. 84-86, Slipi, Jakarta Barat 11420, Indonesia

Tel: +62-21-5681570 (ext. 2606) Fax: +62-21-5681579

E-mail: irena_s_rini@yahoo.com

This article was presented at the PRS Korea on November 8-10, 2019, in Seoul, Korea.

\section{INTRODUCTION}

Defects in the trunk area can have several etiologies, including trauma, tumor resection, infection, and pressure sores. Various methods have been described for the repair of such defects. Currently, the choice of reconstruction method is based on the reconstructive elevator theory, a replacement of the conventional concept of the reconstructive ladder.
However, the use of local flaps is still considered an ideal option for the repair of defects, especially smaller ones. Compared to free tissue transfer, local flap reconstruction requires a shorter operative time and better utilizes local "like" tissue. Additionally, the failure of free flaps involves the total loss of all tissue transferred.

The keystone design perforator island flap, or keystone flap, is a local flap that has become a common option for reconstruc- 


\section{Fig. 1. Traditional classification of the keystone flap}

(A) Skin island flap for defects of up to $2 \mathrm{~cm}$. (B) Division of deep fascia and skin graft for repair of a secondary defect. (C) Double keystone flap (D) undermined up to 50\% of the flap subfascially. Adapted from Behan. ANZ J Surg 2003;73:112-20, with permission John Wiley and Sons [1].
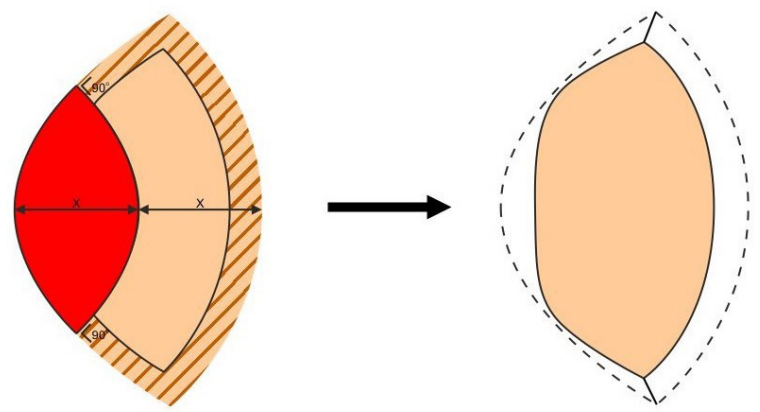

(A)
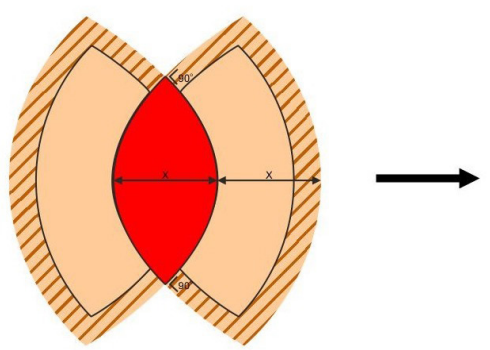

Defect Skin $\mathbb{Z}$ Dissected area
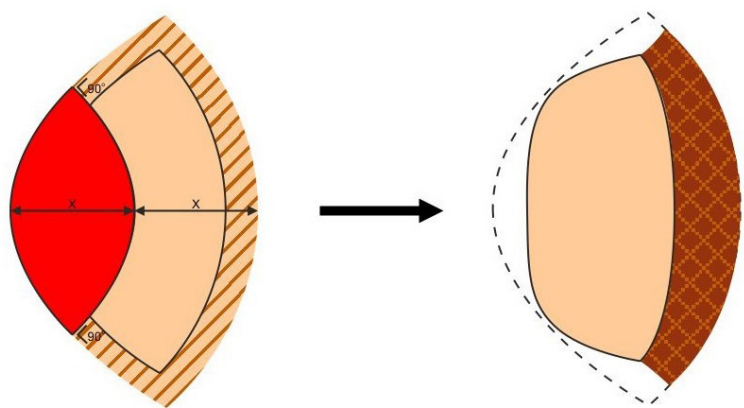

(B)

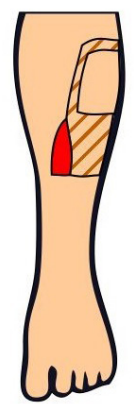

Skin graft

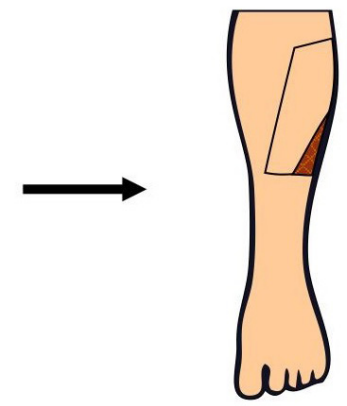

tion. Introduced in 2003, the keystone flap is a multiperforator advancement flap that yields reliable and versatile vascularization. The flap consists of two conjoined VY island flaps that release the longitudinal tension. This increases the laxity within the flap, allowing advancement toward the defect [1,2].

The traditional keystone flap can be further categorized into several subtypes depending on the defect size, deep fascia division, use of a split skin graft to repair the secondary defect, degree of undermining, and use of double flap harvest [1]. The traditional design of a keystone flap is shown in Fig. 1. To date, keystone flaps with or without modifications have been used to repair various defects (including large defects), such as those present due to oncologic resection, trauma, and elective or inflammatory wound excision $[2,3]$. The definition of a large defect varies depending on the region of the body or the skin surface area of the patient; examples include $1 \mathrm{~cm}^{2}$ in infants with myelomeningocele [4], approximately $100 \mathrm{~cm}^{2}$ in the lower extremities, and $380 \mathrm{~cm}^{2}$ in the trunk [5]. An example of a modification to the keystone flap design (the omega variant) is shown in Fig. 2.

One review has been published on the use of the keystone design perforator island flap in the extremities [6]. However, no such review has been published regarding trunk defects. We herein review the rates of keystone flap complications in the repair of trunk defects.

\section{PATIENTS AND METHODS}

We followed the recommendations for interventional reviews provided in the Cochrane Handbook (version 5.1.0). Our work was compliant with the Assessment of Multiple Systematic Reviews, and our report aligned with the principles outlined in the Preferred Reporting Items for Systematic Reviews and MetaAnalyses statement [7]. As a systematic review, this report did not require ethical approval or patient consent.

\section{Inclusion criteria}

All published original studies that described the use of keystone flaps in the repair of trunk defects were included. Duplicate studies were excluded, as were review articles, purely technical descriptions, commentaries, discussions, editorials, and letters or viewpoints. In cases in which multiple articles were written by the same author, we verified that the data from the different publications were not identical; any potential duplicate data were excluded. When studies lacked full online data, we attempted to obtain access to the complete data via direct request 


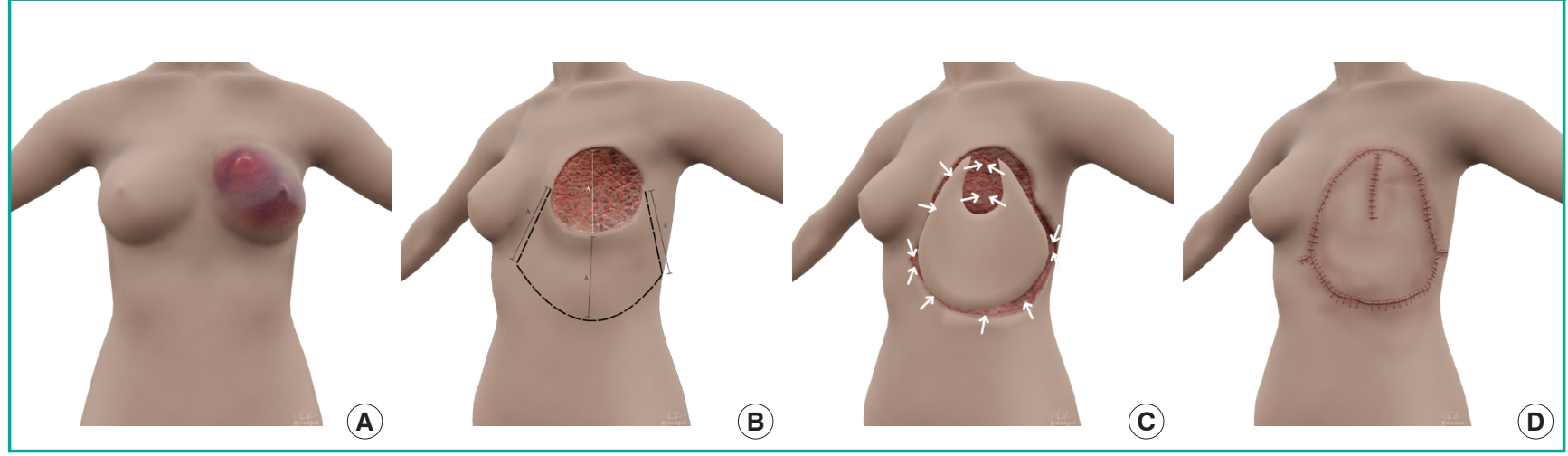

Table 1. Synthesis of data from case studies and case series

\begin{tabular}{|c|c|c|c|c|c|c|}
\hline Author (year) & $\begin{array}{l}\text { Level of } \\
\text { evidence }\end{array}$ & $\begin{array}{l}\text { No. of } \\
\text { cases }\end{array}$ & $\begin{array}{l}\text { No. of } \\
\text { flaps }\end{array}$ & $\begin{array}{l}\text { Mean age of } \\
\text { defect (yr) }\end{array}$ & $\begin{array}{c}\text { Follow-up } \\
\text { duration (mon) }\end{array}$ & Complication rate and types \\
\hline Pelissier et al. (2007) [8] & 4 & 2 & 2 & 31.5 & 4 & No significant complications \\
\hline Khouri et al. (2011) [5] & 4 & 9 & 9 & Not described & Not described & $33.3 \%(n=3)$ : partial flap loss $(n=1)$, dehiscence $(n=2)$ \\
\hline Stone et al. (2015) [9] & 4 & 3 & 3 & 63.7 & Not described & $66.7 \%(n=2)$ : dehiscence $(n=1)$, delayed healing $(n=1)$ \\
\hline Park et al. (2016) [10] & 4 & 5 & 5 & 1.4 day & Not described & No significant complications \\
\hline Mohan et al. (2016) [11] & 4 & 6 & 6 & 64.5 & 1 & $\begin{array}{l}\text { 83.3\% }(n=5) \text { : wound complication }(n=1) \text {, delayed healing }(n=3) \text {, } \\
\text { seroma }(n=1) \text {, hematoma }(n=1) \text {, dehiscence }(n=1)\end{array}$ \\
\hline Lanni et al. (2017) [12] & 4 & 20 & 20 & Not described & Not described & $\begin{array}{l}25 \%(n=5) \text { : wound complication }(n=1) \text {, infection }(n=2) \\
\text { hypertrophic scar }(n=1) \text {, contour deformity }(n=1)\end{array}$ \\
\hline Park et al. (2018) [13] & 4 & 3 & 3 & 27 & Not described & $66.7 \%(n=2)$ : infection $(n=2)$ \\
\hline Donaldson et al. (2018) [4] & 4 & 6 & 6 & 1.67 day & 4-94 & $33.3 \%(n=2)$ : infection $(n=2)$ \\
\hline
\end{tabular}

to the corresponding author. If multiple publications addressed the same study or portions of a study, we ensured that the data from a single study were not counted repeatedly.

\section{Search strategy}

The MEDLINE, Embase, Cochrane Library, and PubMed Central electronic databases were searched for articles published between January 2003 (when the keystone flap technique was first described) and December 2018. This search was conducted using appropriate English-language keywords combined with Boolean logical operators as follows: "keystone flap" OR "keystone design perforator island flap" [Title/Abstract/MeSH Terms]; "keystone flap" and "trunk" [Title/Abstract/MeSH Terms]. The search was not limited; if a foreign-language article was located, every effort was made to obtain an English copy. Studies identified via both manual and electronic searches were listed along with their key information using Microsoft Excel 2018 (Microsoft Corp., Redmond, WA, USA).

\section{Data extraction and study appraisal}

Data were independently extracted by two researchers (AJG and RPM), and disagreements were resolved by consensus. If no consensus could be achieved, the dispute was resolved by one senior author (ISR). The following data were extracted: age, location, and cause of the defect; complications; sample size; and follow-up duration. A level of evidence, as defined by the Oxford Centre for Evidence-Based Medicine, was also determined for each study (Table 1) [4,5,8-13].

\section{RESULTS}

\section{Process outcomes}

In total, 114 references were identified, and eight studies that satisfied our inclusion criteria were included. Fig. 3 presents the study selection process, including the identification, screening, and eligibility assessment steps.

The eight articles involved 54 keystone flaps used in patients with trunk defects (Table 1).

\section{Overview of practice Causes of defects}

The causes of the defects are shown in Fig. 4. Oncologic resection was the most frequent cause $(64.4 \%, \mathrm{n}=29)$, followed by all other causes $(35.6 \%, n=16)$. The oncologic causes are detailed in Fig. 5. 


\section{Fig. 3. Flowchart of article identification and inclusion}

114 Records identified

through database searching

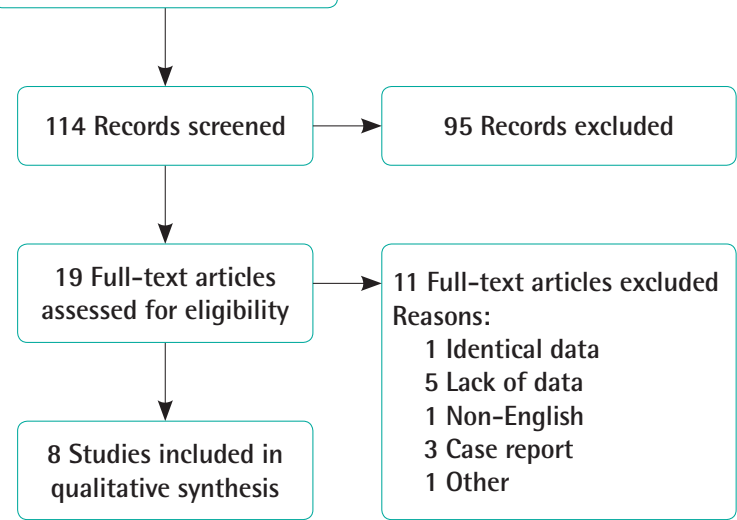

\section{Complications}

The complications noted for all assessed flaps are identified in Fig. 6. Complications occurred in $35.2 \%$ of cases $(n=19)$, and partial flap loss was reported in $1.9 \%$ of cases $(n=1)$. The most

\section{Fig. 4. Causes of defects}

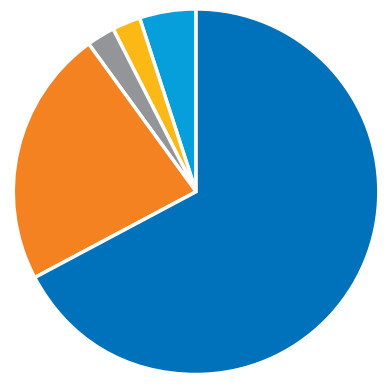

\section{Causes}

Oncologic resection $(n=29)$

Myelomeningocele $(n=11)$

- Spinal stenosis and kyphosis

$(n=1)$

Abdominal wound with enterocutaneous fistula $(\mathrm{n}=1)$

Keloid $(n=3)$

\section{Fig. 5. Oncologic causes of defects}

\section{Oncologic causes}

Angiosarcoma

Dermatofibrosarcoma protuberans

Merkel cell carcinoma

Benign hyalinized spindle mass of the lower back

Squamous cell carcinoma

Sarcoma

Melanoma
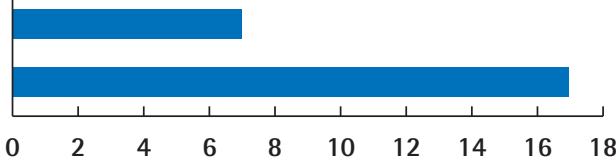

No. of cases

\section{Fig. 6. Types and frequencies of complications}

\section{Complications}

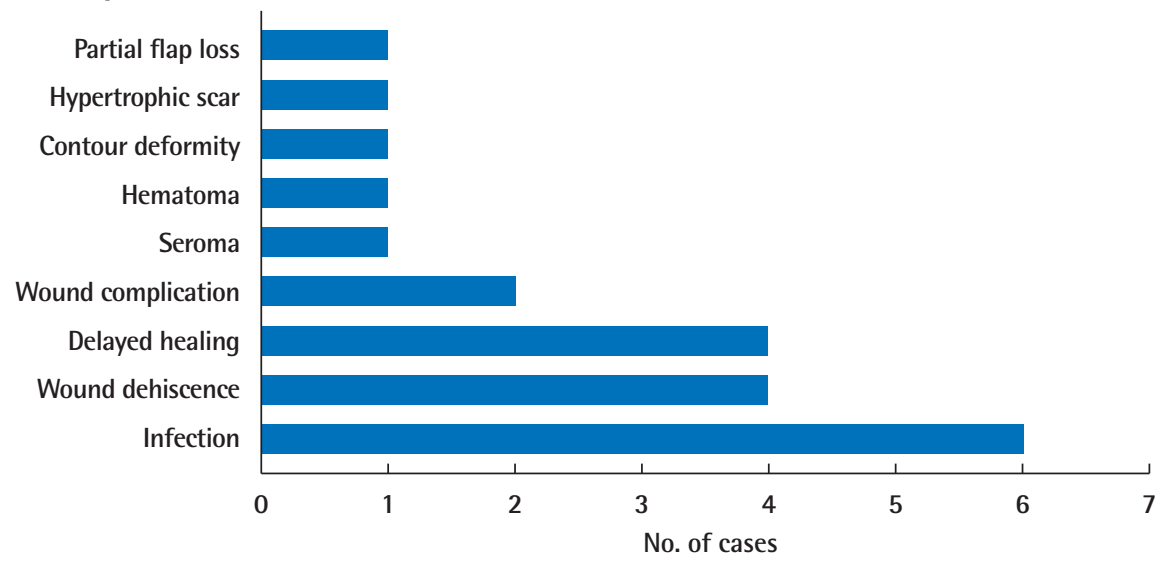


frequent complications were infection $(11.1 \%, \mathrm{n}=6)$, wound dehiscence $(7.4 \%, n=4)$, and delayed healing $(7.4 \%, n=4)$.

\section{DISCUSSION}

Many techniques are available for the reconstruction of trunk defects. Flap options include regional flaps and distant flaps. Many reconstructive surgeons utilize free flaps as their first-line treatment option, especially for large defects of the trunk. Regional flaps (transposition flaps, perforator flaps, and pedicled muscle flaps) for the repair of trunk defects can be approached through the shoulder girdle, paraspinal region, epigastric axis, or pelvic girdle $[14,15]$. Pedicled muscle flaps utilize local "like" tissue and preserve the nerve, muscle, and main vasculature, thus reducing the operation and hospitalization time. Pedicled muscle flaps have been replaced by perforator flaps due to their association with lower donor-site morbidity [6].

In 1988, Kroll and Rosenfield [16] used the term "perforatorbased flap" to describe a new type of flap based on unnamed perforators. In 2003, Behan [1] introduced the keystone flap, another local perforator-based flap. The keystone flap is a fasciocutaneous advancement flap based on randomly-located perforator vessels. The flap and fine perforator dissection do not need to be meticulous. In difficult cases, careful planning is necessary to maximize laxity and ensure defect closure. Several techniques such as releasing the deep fascia, undermining the surrounding wound edges, or adding a skin graft may be needed to facilitate defect closure. Relative to other options, the keystone flap is associated with a shorter operative time, a lower risk of total flap necrosis, more favorable aesthetic results, lower technical difficulty, and lower donor-site morbidity [11,17].

As identified in our literature search, eight articles addressing the use of the keystone flap for trunk reconstruction were published between 2007 and 2018. The keystone flap was most often used after oncologic resection $(64.4 \%, \mathrm{n}=29)$ for melanoma $(37.8 \%, \mathrm{n}=17)$, followed by myelomeningocele $(24.5 \%$, $\mathrm{n}=11)$.

The keystone flap procedure for the repair of trunk defects has a higher complication rate $(35.2 \%)$ than that for the repair of extremity defects (9.6\%) [6]. Complications occurred in 19 cases, including one case of partial flap loss. The most frequent complications were infection $(11.1 \%, \mathrm{n}=6)$, followed by wound dehiscence $(7.4 \%, n=4)$ and delayed healing $(7.4 \%, n=4)$. In comparison, two cases of complete and three cases of partial flap loss occurred in the repair of extremity defects. The higher rates of complications associated with trunk defects may reflect the strict inclusion of all complications, including delayed healing and hematoma.
In one published article, the complication rate for pedicled propeller perforator flaps in the trunk and the perineal region was reviewed. That complication rate was lower (19.3\%) than that found in our review (35.2\%) [18]. However, four cases of total and three cases of partial flap loss occurred in the study of pedicled propeller perforator flaps. Some cases of wound dehiscence also required further revision with skin grafting or local rotation flaps. In a retrospective review, researchers studied the complications associated with the use of free flaps in trunk reconstruction. Eight cases (4.1\%) required reexploration, and two still ended in failure [19]. Although the complication rate of keystone flaps was higher in the present study, major complications such as total flap loss were not seen in our review.

The application of free flaps and pedicled propeller flaps depend on the experience of the surgeon [20]. Time and experience are required to allow the surgeon to salvage the compromised flap and maximize flap survival. These procedures are complicated and require a tool to identify and dissect the perforating vessels [21]. In contrast, keystone flaps offer simpler procedures due to the angiosome concept, as presented by Behan [1]. Keystone flaps are also associated with shorter operating time; two articles reported average operating times that were shorter than 2 hours (104 minutes [4] and 68 minutes [11]). In contrast, the average operating time for free flaps and pedicled propeller flaps is greater than 2 hours [22-24]. Therefore, keystone flaps are highly appealing for trunk reconstruction.

Different indications exist for the various reconstruction methods for trunk defects. For keystone flaps, local tissue laxity is crucial, and these flaps cannot be applied if laxity is insufficient [11]. Pedicled propeller flaps can be used for reconstructions that require flap rotation of more than $90^{\circ}$ based on the territories of the perforasome [25]. Free flaps are still the first choice for the complex reconstruction of large defects [26]. A thorough assessment is needed before choosing the reconstruction method. Keystone flaps can be used for trunk reconstruction, especially if the local tissue laxity is sufficient. Otherwise, other methods such as pedicled muscle flaps or free flaps should be chosen.

This study had several limitations. In the database search, we identified only case series, most of which included low numbers of cases. Additionally, even though all studies involved keystone flaps, the surgical techniques in these articles varied depending on the chosen modifications and the experience of the surgeon, resulting in a lack of standardization. Data regarding patients' comorbidities that could impact complications of keystone flap usage were also unavailable. Future randomized controlled trials on the use of keystone flaps in the repair of trunk defects are needed to ensure similarity in surgical technique and to avoid 
bias due to comorbidities or other confounding factors.

\section{CONCLUSIONS}

Keystone flaps are a breakthrough in the reconstruction of large trunk defects. The success rate is not strongly impacted by the skill and experience of the surgeon, unlike the use of pedicled muscle flaps or free flaps. Furthermore, keystone flaps rarely lead to major complications, such as total or partial flap loss. In conclusion, keystone flaps should be considered as an option in trunk reconstruction.

\section{NOTES}

\section{Conflict of interest}

No potential conflict of interest relevant to this article was reported.

\section{Author contribution}

Conceptualization: IS Rini. Data curation: IS Rini, AJ Gunardi, RP Marsaulina. Formal analysis: IS Rini, AJ Gunardi, RP Marsaulina. Methodology: IS Rini, AJ Gunardi, RP Marsaulina. Project administration: IS Rini. Visualization: IS Rini, T Aryandono, I Dachlan, I Dwiprahasto. Writing - original draft: IS Rini, AJ Gunardi, RP Marsaulina. Writing - review \& editing: all authors.

\section{ORCID}

Irena Sakura Rini https://orcid.org/0000-0003-4173-5911 Alberta Jesslyn Gunardi

https://orcid.org/0000-0002-0169-795X

Renate Parlene Marsaulina https://orcid.org/0000-0001-8294-2090

Teguh Aryandono https://orcid.org/0000-0002-1143-4125 Ishandono Dachlan https://orcid.org/0000-0001-8270-2804 Iwan Dwiprahasto https://orcid.org/0000-0001-9064-9687

\section{REFERENCES}

1. Behan FC. The keystone design perforator island flap in reconstructive surgery. ANZJ Surg 2003;73:112-20.

2. Bhat SP. Keystone flaps in coloured skin: flap technology for the masses? Indian J Plast Surg 2013;46:36-47.

3. Behan FC, Rozen WM, Lo CH, et al. The omega - $\Omega$ - variant designs (types $\mathrm{A}$ and $\mathrm{B}$ ) of the keystone perforator island flap. ANZJ Surg 2011;81:650-2.

4. Donaldson C, Murday HK, Gutman MJ, et al. Long-term follow-up for keystone design perforator island flap for clo- sure of myelomeningocele. Childs Nerv Syst 2018;34:7336.

5. Khouri JS, Egeland BM, Daily SD, et al. The keystone island flap: use in large defects of the trunk and extremities in softtissue reconstruction. Plast Reconstr Surg 2011;127:121221.

6. Huang J, Yu N, Long X, et al. A systematic review of the keystone design perforator island flap in lower extremity defects. Medicine (Baltimore) 2017;96:e6842.

7. Moher D, Liberati A, Tetzlaff J, et al. Preferred reporting items for systematic reviews and meta-analyses: the PRISMA statement. Int J Surg 2010;8:336-41.

8. Pelissier P, Gardet H, Pinsolle V, et al. The keystone design perforator island flap. Part II: clinical applications. J Plast Reconstr Aesthet Surg 2007;60:888-91.

9. Stone JP, Webb C, McKinnon JG, et al. Avoiding skin grafts: the keystone flap in cutaneous defects. Plast Reconstr Surg 2015;136:404-8.

10. Park HS, Morrison E, Lo C, et al. An application of keystone perforator island flap for closure of lumbosacral myelomeningocele defects. Ann Plast Surg 2016;77:332-6.

11. Mohan AT, Rammos CK, Akhavan AA, et al. Evolving concepts of keystone perforator island flaps (KPIF): principles of perforator anatomy, design modifications, and extended clinical applications. Plast Reconstr Surg 2016;137:190920.

12. Lanni MA, Van Kouwenberg E, Yan A, et al. Applying the keystone design perforator island flap concept in a variety of anatomic locations: a review of 60 consecutive cases by a single surgeon. Ann Plast Surg 2017;79:60-7.

13. Park TH, Lee JW, Kim CW. The fortune cookie flap for aesthetic reconstruction after chest keloid resection: a small case series. J Cardiothorac Surg 2018;13:31.

14. Behr B, Wagner JM, Wallner C, et al. Reconstructive options for oncologic posterior trunk defects: a review. Front Oncol 2016;6:51.

15. Hamdi M, Stillaert FB. Pedicled perforator flaps in the trunk. Clin Plast Surg 2010;37:655-65.

16. Kroll SS, Rosenfield L. Perforator-based flaps for low posterior midline defects. Plast Reconstr Surg 1988;81:561-6.

17. Correia B, Costa J, Casanov J, et al. The keystone perforator island flap and its use in complex defects of the trunk: a case report. Rev Port Cir Cardiotorac Vasc 2017;24:77-9.

18. Lazzeri D, Huemer GM, Nicoli F, et al. Indications, outcomes, and complications of pedicled propeller perforator flaps for upper body defects: a systematic review. Arch Plast Surg 2013;40:44-50.

19. Bui DT, Cordeiro PG, Hu QY, et al. Free flap reexploration: 
indications, treatment, and outcomes in 1193 free flaps. Plast Reconstr Surg 2007;119:2092-100.

20. Chang EI. My first 100 consecutive microvascular free flaps: pearls and lessons learned in first year of practice. Plast Reconstr Surg Glob Open 2013;1:e27.

21. Pignatti M, Pasqualini M, Governa M, et al. Propeller flaps for leg reconstruction. J Plast Reconstr Aesthet Surg 2008; 61:777-83.

22. Bravo FG, Schwarze HP. Free-style local perforator flaps: concept and classification system. J Plast Reconstr Aesthet Surg 2009;62:602-9.

23. Hong JP. The use of supermicrosurgery in lower extremity reconstruction: the next step in evolution. Plast Reconstr Surg 2009; 123:230-5.

24. Kneser U, Beier JP, Schmitz M, et al. Zonal perfusion patterns in pedicled free-style perforator flaps. J Plast Reconstr Aesthet Surg 2014;67:e9-17.

25. Pignatti M, Ogawa R, Hallock GG, et al. The "Tokyo" consensus on propeller flaps. Plast Reconstr Surg 2011;127: 716-22.

26. Bekara F, Herlin C, Mojallal A, et al. A systematic review and meta-analysis of perforator-pedicled propeller flaps in lower extremity defects: identification of risk factors for complications. Plast Reconstr Surg 2016;137:314-31. 